\title{
MÖSSBAUER STUDY OF SPIN ALIGNMENT IN SUBSTITUTED LITHIUM FERRITES
}

\author{
C. R. ABELEDO (*) and R. B. FRANKEL \\ Francis Bitter National Magnet Laboratory Massachussetts Institute of Technology (**) \\ Cambridge, Massachussett 02139, U. S. A.
}

\begin{abstract}
Résumé. - Pour expliquer la décroissance du moment magnétique dans des ferrites de lithium substitués au zinc, Dionne a proposé un modèle qui tient compte d'un canting des moments situés sur les sites B lorsque le zinc substitué est sur les sites A. On utilise ici la spectroscopie Mössbauer sous champ magnétique extérieur pour rechercher l'existence du canting dans le ferrite $\left(\mathrm{Li}_{0,5} \mathrm{Fe}_{0,5}\right)_{1-x} \mathrm{Zn}_{x} \mathrm{Fe}_{2} \mathrm{O}_{4}$ avec $x=0$ et $x=0,3$.

Les échantillons utilisés sont soit des poudres polycrystallines soit des disques amincis jusqu'à $0,1 \mathrm{~mm}$ tirés de pavés pressés.

Dans les échantillons $x=0$ les raies Mössbauer $\Delta m=0$ disparaissent pour des champs appliqués inférieurs à $10 \mathrm{kOe}$. Pour $x=0,3$ ces raies disparaissent pour des champs appliqués voisins de $15 \mathrm{kOe}$. Ces resultats semblent indiquer un léger canting dans les échantillons $x=0,3$.
\end{abstract}

\begin{abstract}
To explain the decrease of magnetic moment in zinc substituted lithium ferrites Dionne has proposed a model which includes canting of the B sublattice moments as zinc is substituted in the A sublattice. Mössbauer spectroscopy in external magnetic fields is applied to investigate the existence of canting in $\left(\mathrm{Li}_{0,5} \mathrm{Fe}_{0,5}\right)_{1-x} \mathrm{Zn}_{x} \mathrm{Fe}_{2} \mathrm{O}_{4}$ with $x=0$ and $x=0.3$. The samples used were either polycrystalline powders or circular disks cut from pressed blocks and lapped down to a thickness of $0.1 \mathrm{~mm}$. In the $x=0$ samples the $\Delta m=0$ Mössbauer lines vanish for external fields below $10 \mathrm{k} 0 \mathrm{e}$. For $x=0.3$ the $\Delta m=0$ lines vanish at external magnetic fields close to $15 \mathrm{kOe}$. These results seem to indicate a small canting angle in the $x=0.3$ samples.
\end{abstract}

1. Introduction. - The existence of triangular (or canted) spin arrangements in ferrimagnets has been the subject of extensive investigations since Yafet and Kittel (YK) postulated their existence [1]. Triangular arrangements arise when A-A or B-B interactions are comparable to the A-B intersublattice interactions. Experimental evidence for triangular arrangements has been obtained by neutron diffraction [2,3], high field differential susceptibility [4] and Mössbauer spectroscopy [5-8] in systems such as $\mathrm{MnFe}_{2-x} \mathrm{Cr}_{x} \mathrm{O}_{4}$, $\mathrm{CuCr}_{2} \mathrm{O}_{4}, \mathrm{FeCr}_{2} \mathrm{O}_{4}, \mathrm{NiFe}_{2-x} \mathrm{Cr}_{x} \mathrm{O}_{4}, \mathrm{Ni}_{1-x} \mathrm{Zn}_{x} \mathrm{Fe}_{2} \mathrm{O}_{4}$.

On the basis of the YK model, Geller et al. [9] have interpreted their magnetization data on substituted yttrium-iron garnets (YIG) assuming that when nonmagnetic ions substitute $\mathrm{Fe}^{3+}$ exclusively in one sublattice, the moments of the $\mathrm{Fe}^{3+}$ ions in that sublattice remain parallel while the weakened average $A-D$ interactions and the intrasublattice interactions lead to random canting of the $\mathrm{Fe}^{3+}$ moments in the non substituted sublattice. Later, Rosencwaig [10] proposed a statistical model which takes into account both chemical disorder and the alteration of inter- and intrasublattice interactions. According to

(*) Visiting scientist at FBNM. Present address : NISALCO, Madero 1020, Buenos Aires, Argentina.

(**) Supported bv the National Science Foundation. his model canting will occur in the sublattice not experiencing diamagnetic substitution and the average canting angle should increase from 0 to $\pi$ with increasing diamagnetic substitution. Dionne $[11,12]$ has applied the Geller model to calculate molecular field coefficients and magnetization-temperature curves in substituted YIG's and has later [13] extended his model to $\mathrm{Zn}$ substituted lithium ferrite where he can fit the magnetization data assuming that that all $\mathrm{Zn}^{2+}$ ions go into tetrahedral $\mathrm{A}$ sites and that $\mathrm{Fe}^{3+}$ ions in the $\mathrm{B}$ sublattice are canted.

Mössbauer spectroscopy has been used previously [5-8] to prove or rule out the existence of canted spin structures in several ferrimagnetic systems. The basis of the method is the following: a typical Mössbauer spectrum in a randomly magnetized magnetic material consists of six lines (see Fig. 1 (top)). The second and fifth lines correspond to nuclear transitions with no change in nuclear magnetic quantum number $m$ $(\Delta m=0)$. The selection rules for such transitions indicate that the transition is forbidden for gamma rays propagating parallel to the direction of the magnetic field at the nucleus. Therefore, if spectra are taken in an external magnetic field which is applied parallel to the direction of propagation of the $y$ rays the intensity of the $\Delta m=0$ lines is a measurement of the non collinearity between the applied field and the 


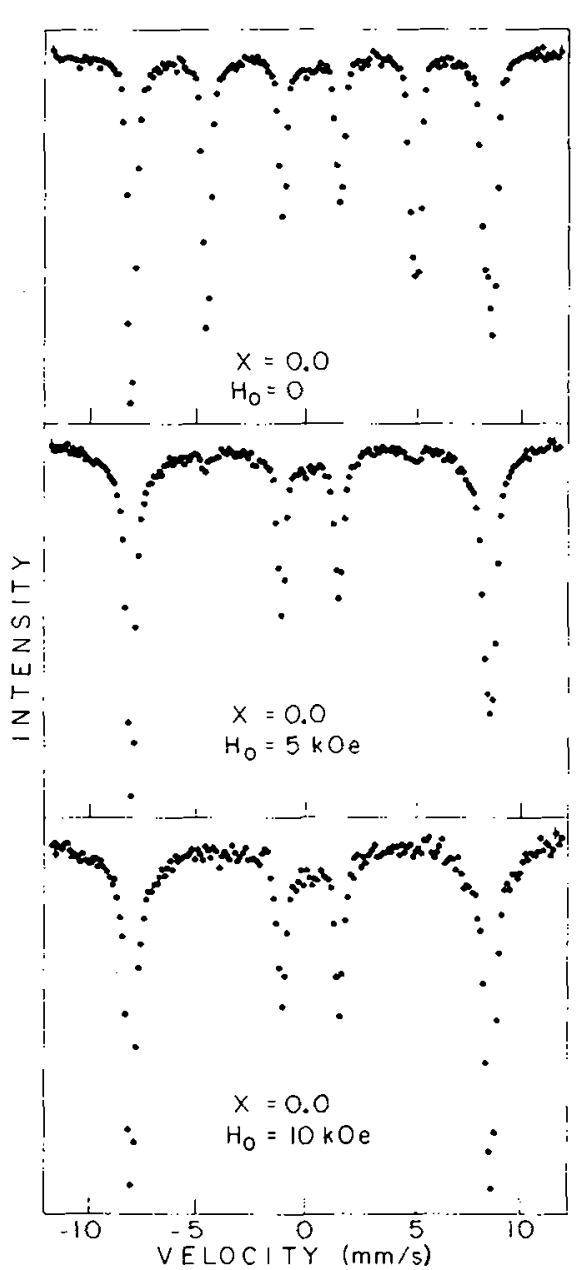

FIG. 1. - Mössbauer spectra for powdered lithium ferrite in external magnetic fields $H_{0}=0 ; 5$ and $10 \mathrm{kOe}$.

magnetic moment at the iron sites. Employing this method Frankel and Chappert [5] were able to show the existence of triangular spin arrangements in $\mathrm{NiFe}_{0.3} \mathrm{Cr}_{1.7} \mathrm{O}_{4}$ and the collinearity of magnetic moments in $\mathrm{NiFe}_{2} \mathrm{O}_{4}$. More recently triangular arrangements have been demonstrated in $\mathrm{Ni}_{1-x} \mathrm{Zn}_{x} \mathrm{Fe}_{2} \mathrm{O}_{4}$ [6-8].

In the present paper we report the results of Mössbauer spectroscopy in external magnetic fields in substituted lithium ferrites $\left(\mathrm{Li}_{0.5} \mathrm{Fe}_{0.5}\right)_{1-x} \mathrm{Zn}_{x} \mathrm{Fe}_{2} \mathrm{O}_{4}$. This system is of special interest for several reasons $: a$ ) since there is only one kind of magnetic ions they are simpler than other substituted spinels,

b) canting effects had been postulated by Dionne for this system, $c$ ) canting had been found in the closely related $\mathrm{Ni}-\mathrm{Zn}$ ferrite system and last but not least lithium ferrites have acquired considerable technical importance as square loop materials for microwave devices.

In a previous Mössbauer investigation in this system Young and Smit [14] found that spectra taken at $22^{\circ}$ and $330^{\circ} \mathrm{C}$ are fit by a superposition of components due to $\mathrm{Fe}^{3+}$ ions on tetrahedral sites and on octahedral sites with different numbers of magnetic neighbours.
On the basis of the Mössbauer results (in zero applied magnetic field) they obtain fit between calculated and experimental magnetizations without assuming spin canting.

2. Experimental. - Polycrystalline lithium ferrite samples were kindly supplied by R. G. West (Trans. Tech. Inc.). Their preparation has been described elsewhere [5]. Spectra were taken on two types of samples: a) finely ground (mesh 325 ) powders and, $b$ ) thin circular plates were cut from the pressed and sintered blocks and were carefully lapped down to a thickness of $0.1 \mathrm{~mm}$.

Mössbauer spectra were taken in a conventional constant acceleration spectrometer. The source used was $100 \mathrm{mCi}{ }^{57} \mathrm{Co}: \mathrm{Rh}$. The absorbers were placed in the center of a superconducting magnet. The magnetic field is parallel to the direction of propagation of the $\gamma$ rays.

3. Results. - Figure 1 shows Mössbauer spectra of powdered lithium ferrite in external magnetic fields. For $H_{0}=10 \mathrm{kOe}$ the sample is magnetized along the magnetic field direction and the $\Delta m=0$ lines have vanished. Figures 2 and 3 show the spectra

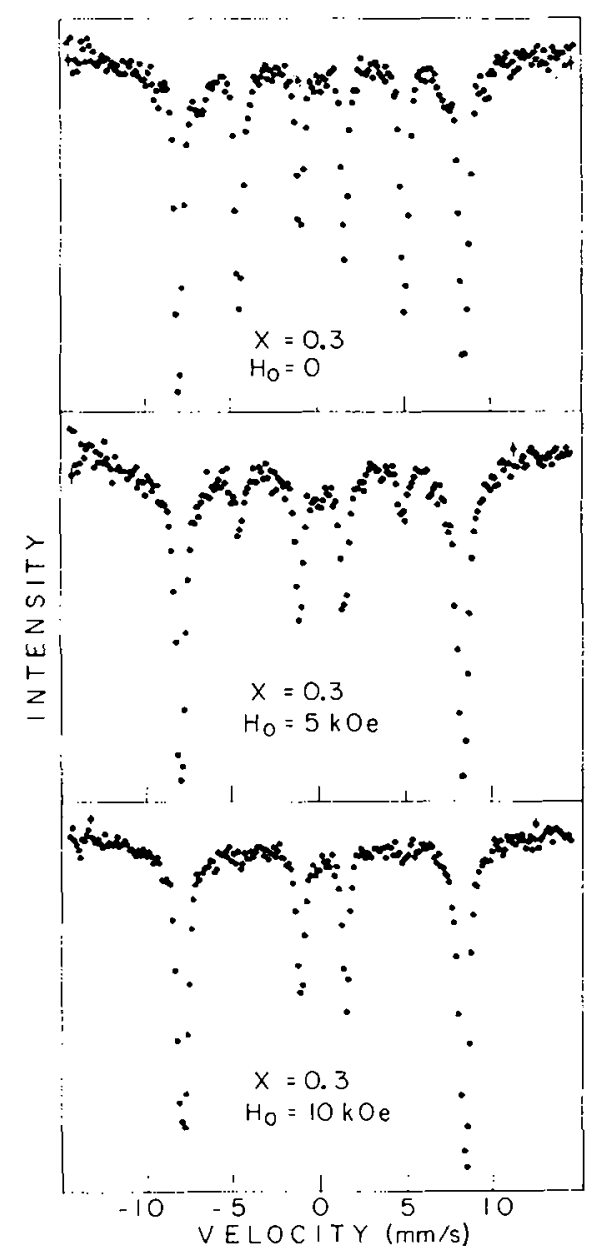

FIG. 2. - Mössbauer spectra of powdered lithium-zinc ferrite $(x=0.3)$ in external magnetic fields $H_{0}=0 ; 5$ and $10 \mathrm{kOe}$. 


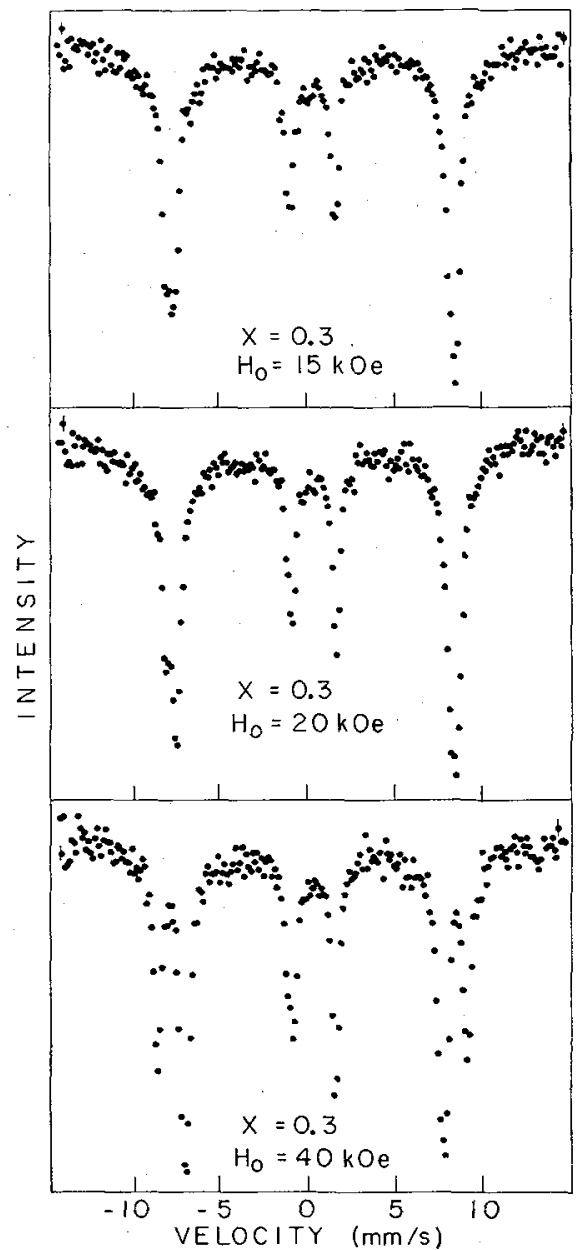

FIG. 3. - Mössbauer spectra of powdered lithium-zinc ferrite $(x=0.3)$ in external magnetic fields $H_{0}=15 ; 20$ and $40 \mathrm{kOe}$.

of the powdered samples for $\left(\mathrm{Li}_{0.5} \mathrm{Fe}_{0.5}\right)_{0.7} \mathrm{Fe}_{2} \mathrm{Zn}_{0.3} \mathrm{O}_{4}$ (hereafter referred to as the $x=0.3$ sample). Here the field necessary to suppress the $\Delta m=0$ lines is estimated as close to $15 \mathrm{kOe}$. The difference is seen more clearly in the spectra taken with the lapped disks (see Figs. 4 and 5). We note that for $H_{0}=5 \mathrm{kOe}$ the intensity of the $\Delta m=0$ lines in the lapped disk spectra is much larger than for the powdered samples reflecting the difficulty in magnetizing the disk in a direction perpendicular to its plane. However, for $H_{0}=10 \mathrm{kOe}$ the samples are magnetized and the $\Delta m=0$ lines are suppressed in the unsubstituted samples whereas we find nonvanishing $\Delta m=0$ lines close to $15 \mathrm{kOe}$, in the substituted samples.

The values of the magnetic field necessary to suppress the $\Delta m=0$ lines in the substituted lithium ferrites are much smaller than those found in nickel zinc ferrites. A field of $15 \mathrm{kG}$ is not very much above that usually found as necessary ot magnetize polycrystalline samples. However, since it has been found [15] that the magnetocrystalline anisotropy in lithium zinc ferrites decreases with increasing $\mathrm{Zn}$ content one would expect that the substituted samples would magnetize more easily than the pure lithium ferrite.

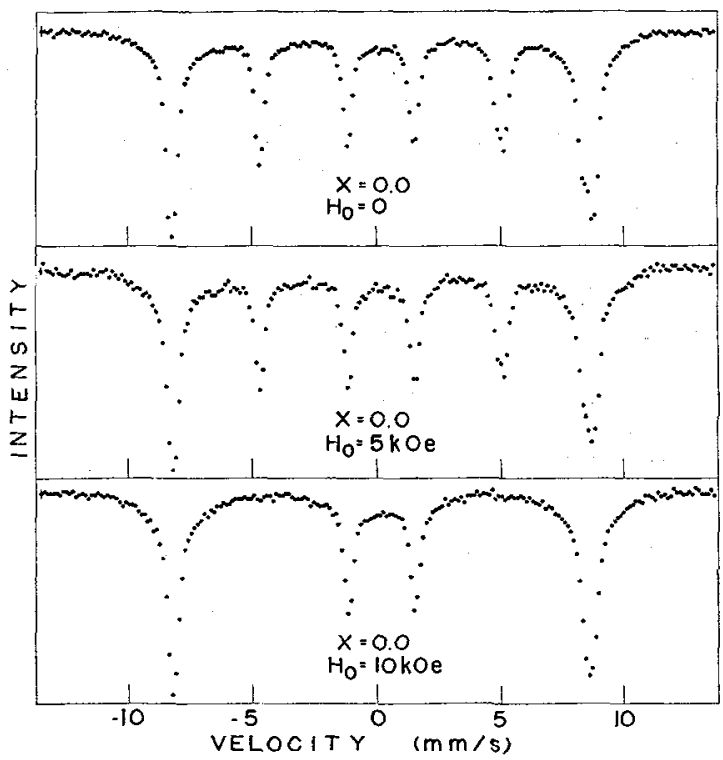

FIG. 4. - Mössbauer spectra of a $0.1 \mathrm{~mm}$ thick disc of sintered lithium ferrite in external magnetic fields $H_{0}=0 ; 5$ and $10 \mathrm{kOe}$

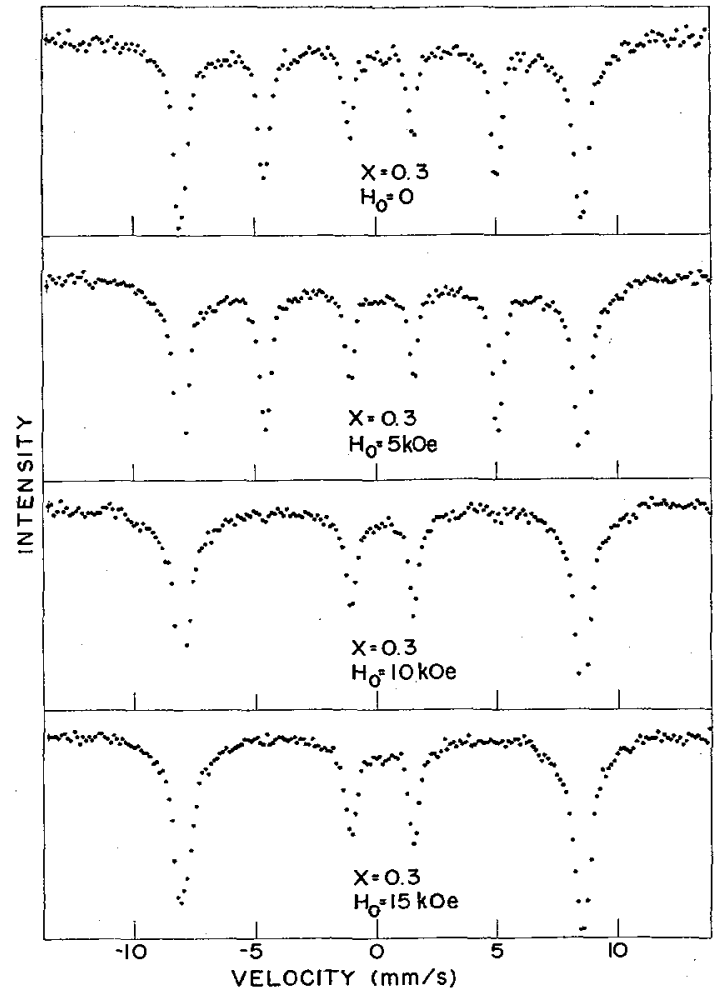

FIG. 5. - Mössbauer spectra of a $0.1 \mathrm{~mm}$ thick disc of sintered lithium-zinc ferrite $(x=0.3)$ in external magnetic fields $H_{0}=0$, $5 ; 10$ and $15 \mathrm{kOe}$.

The fact that we find the opposite effect could perhaps be due to a small degree of canting in the substituted sample. The results are not conclusive, however, and high field magnetization studies or Mössbauer spectra in single crystal samples could probably illuminate the situation further. 


\section{References}

[1] YAfet, Y. and Kittel, C., Phys Rev. B 7 (1952) 290.

[2] Prince, E., Acta Crystallogr. 10 (1957) 554.

[3] Satya Murthy, N. S., Natera, M. G., Yousef, S. I., Begum, R. J. and Srivastava, C. M., Phys. Rev. 181 (1969) 969.

[4] JaCoBs, I. S., J. Phys. \& Chem. Solids 15 (1960) 54.

[5] Chappert, J. and Frankel, R. B., Phys. Rev. Lett. 19 (1967) 570.

[6] Daniels, J. M. and Rosencwaig, A., Can.J. Phys. 48 (1970) 381.

[7] Pexit, G. A., Solid State Commun. 13 (1973) 161.
[8] Piekoszewski, J., Dabrowski, L., and Suwalski, J., Solid State Commun. 16 (1975) 75.

[9] Geller, S., Williams, H. J., Espinosa, G. P. and Sherwood, R. C., Bell System Tech. J. 43 (1964) 565.

[10] Rosencwaig, A., Can. J. Phys. 48 (1970) 2857.

[11] Dionne, G. F., J. Appl. Phys. 41 (1970) 4874.

[12] Dionne, G. F., J. Appl. Phys. 42 (1971) 2142.

[13] Dronne, G. F., J. Appl. Phys. 45 (1974) 3621.

[14] Young, J. W., and Smit, J., J. Appl. Phys. 42 (1971) 2344.

[15] West, R. G. and Blankenship, A. C., J. Am. Ceram. Soc. 50 (1967) 343. 